\title{
SPATIAL DISTRIBUTION OF
}

\section{PERFLUOROALKYL CONTAMINANTS IN LAKE TROUT FROM THE GREAT LAKES}

Vasile I. Furdui ${ }^{1}$, Naomi L. Stock ${ }^{1}$, David Ellis ${ }^{1}$, Craig M. Butt ${ }^{1}$, D. Michael Whittle ${ }^{2}$, Patrick W. Crozier $^{3}$, Eric J. Reiner ${ }^{3}$, Derek C. G. Muir ${ }^{4}$ and Scott A. Mabury $*^{1}$

${ }^{1}$ University of Toronto, Department of Chemistry, 80 St. George Street, Toronto, Ontario, M5S 3H6,

${ }^{2}$ Department of Fisheries \& Oceans, Great Lakes Laboratory for Fisheries and Aquatic Sciences, 867 Lakeshore Road, Burlington, ON, L7R 4A6

${ }^{3}$ Ontario Ministry of the Environment, Laboratory Services Branch, 125 Resources Road, Etobicoke, Ontario, M9P 3 V6

and

${ }^{4}$ Environment Canada, Water Science and Technology Directorate, 867 Lakeshore Road, Burlington, Ontario, L7R 4A6

*Corresponding author e-mail: smabury@chem.utoronto.ca; phone/fax: (416) 978-3596.

\section{SUPPORTING INFORMATION}

Table S1. Sample details.

Page

Table S2. LC-MS-MS details.

SI- 2

Discussion. Development of the fluorophilicity clean-up step.

SI- 3

Table S3. Comparison of spike and recovery data for the clean-up step

SI- 4

Table S4. Average recovery of each analyte $( \pm \mathrm{SE})$, method detection limit (MDL) and the percentage of non detected (n.d.) responses................................... SI- 7

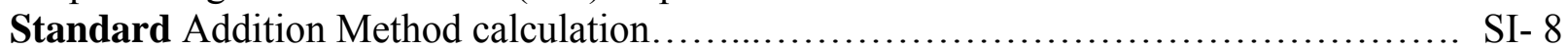

Table S5. Overall analytical method uncertainty for each analyte...................... SI- 9

Figure S1. Correlation between the level of PFOS and PFDS in whole body homogenates of lake trout from the Great Lakes.

SI-10 STATISTICS: Graphs and results of the paired t-test for each analyte determined with standard addition and internal standard....

Table S6: Average Concentrations of PFCs in water samples from the Great Lakes. 
Table S1. Sample details

\begin{tabular}{|c|c|c|c|c|c|}
\hline Sample & Lake & Total length (cm) & Weight (g) & Sex & Age (years) \\
\hline 1 & Erie & 62 & 2780 & F & 4 \\
\hline 2 & & 58 & 2335 & $\mathrm{~F}$ & 4 \\
\hline 3 & & 57 & 2504 & M & 4 \\
\hline 4 & & 62 & 2719 & M & 4 \\
\hline 5 & & 58 & 2571 & M & 4 \\
\hline 6 & & 56 & 2078 & M & 4 \\
\hline 7 & Huron & 45 & 1080 & $\mathrm{M}$ & 4 \\
\hline 8 & & 49 & 1359 & M & 4 \\
\hline 9 & & 48 & 1185 & M & 4 \\
\hline 10 & & 47 & 1043 & $\mathrm{M}$ & 4 \\
\hline 11 & & 43 & 821 & M & 4 \\
\hline 12 & & 49 & 1273 & M & 4 \\
\hline 13 & & 49 & 1083 & M & 4 \\
\hline 14 & & 44 & 897 & M & 4 \\
\hline 15 & & 61 & 2491 & M & 4 \\
\hline 16 & & 52 & 1676 & $\mathrm{M}$ & 4 \\
\hline 17 & Michigan & 46 & 1052 & $\mathrm{M}$ & 4 \\
\hline 18 & & 44 & 1121 & M & 4 \\
\hline 19 & & 56 & 1840 & M & 4 \\
\hline 20 & & 55 & 1955 & M & 4 \\
\hline 21 & & 57 & 2103 & $\mathrm{~F}$ & 4 \\
\hline 22 & & 52 & 1610 & M & 4 \\
\hline 23 & & 49 & 1403 & M & 4 \\
\hline 24 & & 50 & 1606 & M & 4 \\
\hline 25 & & 48 & 1210 & M & 4 \\
\hline 26 & & 46 & 1370 & M & 4 \\
\hline 27 & Ontario & 54 & 1715 & $\mathrm{~F}$ & 4 \\
\hline 28 & & 60 & 2774 & M & 4 \\
\hline 29 & & 57 & 1575 & $\mathrm{~F}$ & 4 \\
\hline 30 & & 58 & 1980 & $\mathrm{~F}$ & 4 \\
\hline 31 & & 50 & 1616 & M & 4 \\
\hline 32 & & 58 & 2338 & M & 4 \\
\hline 33 & & 61 & 2896 & M & 4 \\
\hline 34 & & 54 & 1978 & M & 4 \\
\hline 35 & & 52 & 1324 & $\mathrm{~F}$ & 4 \\
\hline 36 & & 61 & 2694 & M & 4 \\
\hline 37 & Superior & 50 & 1152 & $\mathrm{M}$ & 4 \\
\hline 38 & & 51 & 1029 & M & 4 \\
\hline 39 & & 51 & 1231 & M & 4 \\
\hline 40 & & 48 & 912 & M & 4 \\
\hline 41 & & 45 & 809 & M & 4 \\
\hline 42 & & 51 & 1025 & M & 4 \\
\hline 43 & & 42 & 663 & M & 4 \\
\hline 44 & & 48 & 1072 & M & 4 \\
\hline 45 & & 55 & 1457 & $\mathrm{~F}$ & 4 \\
\hline 46 & & 47 & 1107 & $\mathrm{M}$ & 4 \\
\hline
\end{tabular}


Table S2. LC-MS-MS details

\begin{tabular}{|c|c|c|c|c|c|c|c|}
\hline \multirow{2}{*}{ Acronym } & \multirow{2}{*}{$\begin{array}{l}\text { Retention Time } \\
\text { (min) }\end{array}$} & \multicolumn{2}{|c|}{ MRM Transition $\left(\mathrm{m} \mathrm{z}^{-1}\right)$} & \multirow{2}{*}{$\begin{array}{l}\text { DT } \\
\text { (ms) }\end{array}$} & \multirow{2}{*}{$\begin{array}{l}\text { DP } \\
\text { (V) }\end{array}$} & \multirow{2}{*}{$\begin{array}{l}\text { CE } \\
\text { (V) }\end{array}$} & \multirow{2}{*}{$\begin{array}{c}\text { CXP } \\
\text { (V) }\end{array}$} \\
\hline & & Parent & Product & & & & \\
\hline PFHxS & 1.45 & 399 & 99 & 25 & -87 & -57 & -10 \\
\hline PFOS & 1.97 & 499 & 99 & 40 & -103 & -75 & -10 \\
\hline PFDS & 3.42 & 599 & 99 & 40 & -115 & -86 & -15 \\
\hline PFOSA & 3.53 & 498 & 78 & 20 & -84 & -79 & -11 \\
\hline PFHpA & 1.46 & 363 & 319 & 20 & -43 & -14 & -9 \\
\hline PFOA & 1.66 & 413 & 369 & 20 & -44 & -14 & -9 \\
\hline PFNA & 2.00 & 463 & 419 & 20 & -44 & -16 & -9 \\
\hline PFDA & 2.56 & 513 & 469 & 25 & -54 & -15 & -9 \\
\hline PFUnA & 3.44 & 563 & 519 & 25 & -49 & -16 & -9 \\
\hline PFDoA & 4.74 & 613 & 569 & 30 & -50 & -18 & -11 \\
\hline PFTrA & 5.63 & 663 & 619 & 30 & -55 & -19 & -11 \\
\hline PFTeA & 6.36 & 713 & 669 & 30 & -60 & -20 & -11 \\
\hline PFPA & 6.79 & 763 & 719 & 30 & -60 & -20 & -11 \\
\hline $8: 2$ FTCA & 2.18 & 477 & 393 & 30 & -57 & -15 & -8 \\
\hline 10:2 FTCA & 3.98 & 577 & 493 & 30 & -57 & -15 & -8 \\
\hline 8:2 FTUCA & 2.18 & 457 & 393 & 20 & -45 & -18 & -9 \\
\hline 10:2 FTUCA & 3.98 & 557 & 493 & 20 & -45 & -20 & -7 \\
\hline${ }^{13} \mathrm{C}_{4}-\mathrm{PFOS}$ & 1.97 & 503 & 99 & 40 & -60 & -78 & -5 \\
\hline${ }^{13} \mathrm{C}_{2}$-PFOA & 1.73 & 415 & 370 & 20 & -44 & -14 & -9 \\
\hline${ }^{13} \mathrm{C}_{4}$-PFOA & 1.73 & 417 & 372 & 20 & -44 & -14 & -9 \\
\hline${ }^{13} \mathrm{C}_{5}$-PFNA & 1.98 & 468 & 423 & 25 & -44 & -14 & -11 \\
\hline${ }^{13} \mathrm{C}_{2}$-PFDA & 2.52 & 515 & 470 & 25 & -55 & -16 & -13 \\
\hline${ }^{13} \mathrm{C}_{2}-8: 2$ FTUCA & 2.18 & 459 & 394 & 20 & -45 & -18 & -9 \\
\hline${ }^{13} \mathrm{C}_{2}-10: 2$ FTUCA & 3.97 & 559 & 494 & 20 & -45 & -20 & -7 \\
\hline
\end{tabular}




\section{Development of the Fluorophilicity Clean-up Step}

A variety of fluorosolvents were explored in the development of the fluorophilicity cleanup step. The efficacy of individual fluorosolvents was evaluated by performing a set $(n=3)$ of spike and recovery experiments and comparing to the results obtained for a set $(n=3)$ of spike and recovery experiments using only methyl-tert-butyl ether (MTBE) (eg. no clean-up step). Spike and recovery experiments were preformed using $\sim 0.5 \mathrm{~g}$ sub-sections of liver from a single ocean-dwelling fish. Immediately prior to extraction, homogenates were spiked with $\sim 20 \mathrm{ng}$ of a mixed standard of perfluoroalkyl analytes. One unspiked homogenate was extracted and analyzed with each set to correct for endogenous liver concentrations.

In the initial round of evaluation, three fluorosolvents from three distinct chemical classes, were used: 1,1,1,3,3,3-hexafluoro-2-propanol (HFP, 99\%), perfluorodecalin (95\%) and octafluorotoluene (98\%) (all purchased from Sigma-Aldrich, Oakville, ON). Extraction recoveries for all fluorosolvents are presented in Table S3. Very poor analyte recoveries were obtained with the use of perfluorodecaline and octafluorotoluene, and results were not quantified. Extraction recoveries of all analytes using employing the HFP clean-up were greater than those obtained using only MTBE, indicating the usefulness of HFP as a solvent for the fluorophilicity clean-up step.

In the second round of evaluation, the efficacy of HFP was compared with other fluorinated alcohols: 2,2,3,3,4,4,4-heptafluoro-1-butanol (98\%) and 2,2,3,3,4,4,5,5,-octafluoro-1pentanol (98\%) and a fluorinated alkane: octadecafluorooctane (98\%)(all purchased from SigmaAldrich, Oakville, ON). Extraction recoveries using the heptafluoro-1-butanol (Table S3) were generally larger than $100 \%$ with large relative standard deviation values. This is likely a function of the large variability of the liver sample, but may also indicate contamination of the fluorosolvent itself. Use of the octafluoro-1-pentanol was impractical given its low volatility (evaporation of only $0.5 \mathrm{~mL}$ in more than 2 hours under a stream of high purity nitrogen).

In summary, extraction recoveries of all analytes using employing HFP, were superior to those obtained using only MTBE and to all other fluorosolvents investigated, demonstrating the effectiveness of HFP for use as a fluorophilicity clean-up step. The HFP fluorophilicity clean-up 
step method has recently been used for the extraction of liver from arctic ringed seals (1), where suitable extraction recoveries were obtained.

It should be noted that the extraction recoveries of individual perfluoroalkyl analytes determined in the development of the fluorophilicity clean-up step are slightly higher than those obtained for the whole body homogenates calculated. This variability is probably the results of several factors including differences in sample matrix, differences in analytical methodology, and different individuals completing the extraction recovery experiments.

(1) Butt, C. M., Muir, D. C. G., Stirling, I., Kwan, M. and Mabury S. A. Rapid response of arctic ringed seals to changes in perfluoroalkyl production. Environ. Sci. Technol. 2006, ASAP. 
Table S3. Comparison of spike and recovery data for perfluoroalkyl analytes spiked into $\sim 0.5 \mathrm{~g}$ of fish liver, with and without the use of fluorophilicity clean-up step, using a variety of flourosolvents.

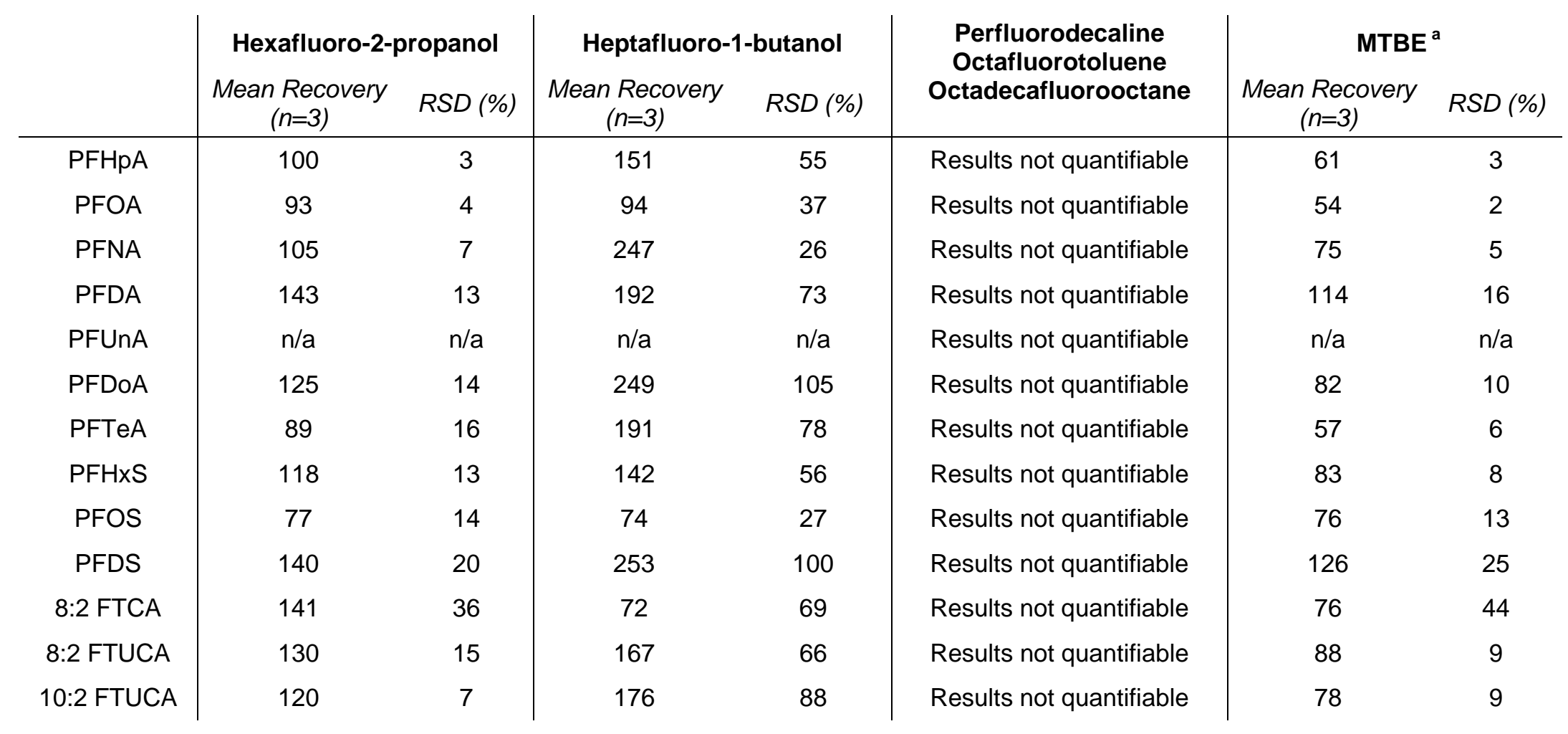

${ }^{\text {a }}$ Represents spike and recovery performed without the addition of fluorophilicity clean-up step 
Table S4. Average recovery of each analyte $( \pm \mathrm{SE})$, method detection limit (MDL) and the percentage of non detected (n.d.) responses (Table 1).

\begin{tabular}{cccc}
\hline Analyte & $\begin{array}{c}\text { Recovery } \\
\mathbf{( \% )}\end{array}$ & $\begin{array}{c}\text { MDL } \\
\mathbf{( p g} / \mathbf{g})\end{array}$ & $\begin{array}{c}\text { n.d. samples } \\
\mathbf{( \% )}\end{array}$ \\
\hline PFHpA & $69 \pm 7$ & 16 & 65 \\
PFOA & $86 \pm 4$ & 4 & 0 \\
PFNA & $89 \pm 4$ & 2.4 & 2 \\
PFDA & $97 \pm 3$ & 3.2 & 0 \\
PFUnA & $75 \pm 3$ & 2.4 & 0 \\
PFDoA & $102 \pm 5$ & 3.2 & 2 \\
PFTrA & - & 3.2 & 0 \\
PFTeA & $140 \pm 4$ & 3.2 & 0 \\
PFPA & - & 8 & 11 \\
PFHxS & $65 \pm 13$ & 10 & 67 \\
PFOS & $70 \pm 5$ & 3.2 & 0 \\
PFDS & $102 \pm 7$ & 1 & 11 \\
PFOSA & $44 \pm 3$ & 1.8 & 0 \\
$8: 2$ FTUCA & $95 \pm 8$ & 4 & 1 \\
$10: 2$ FTUCA & $121 \pm 6$ & & 61 \\
\hline
\end{tabular}




\section{STANDARD ADDITION METHOD}

\section{Example: PFDA in a fish sample from Lake Erie}

$\mathrm{DF}=$ Dilution factor of the extract used $=50$

$\mathrm{FV}=$ Final volume of extract $=1000 \mu \mathrm{L}=10^{-3} \mathrm{~L}$

$\mathrm{m}=$ mass of tissue (wet weight of whole body homogenate) $=0.3785 \mathrm{~g}$

Area (counts) $=1723 \times$ Amount Added $\left(\mathrm{ng} \mathrm{L}^{-1}\right)+38388$

$$
\mathrm{R}^{2}=0.9997
$$

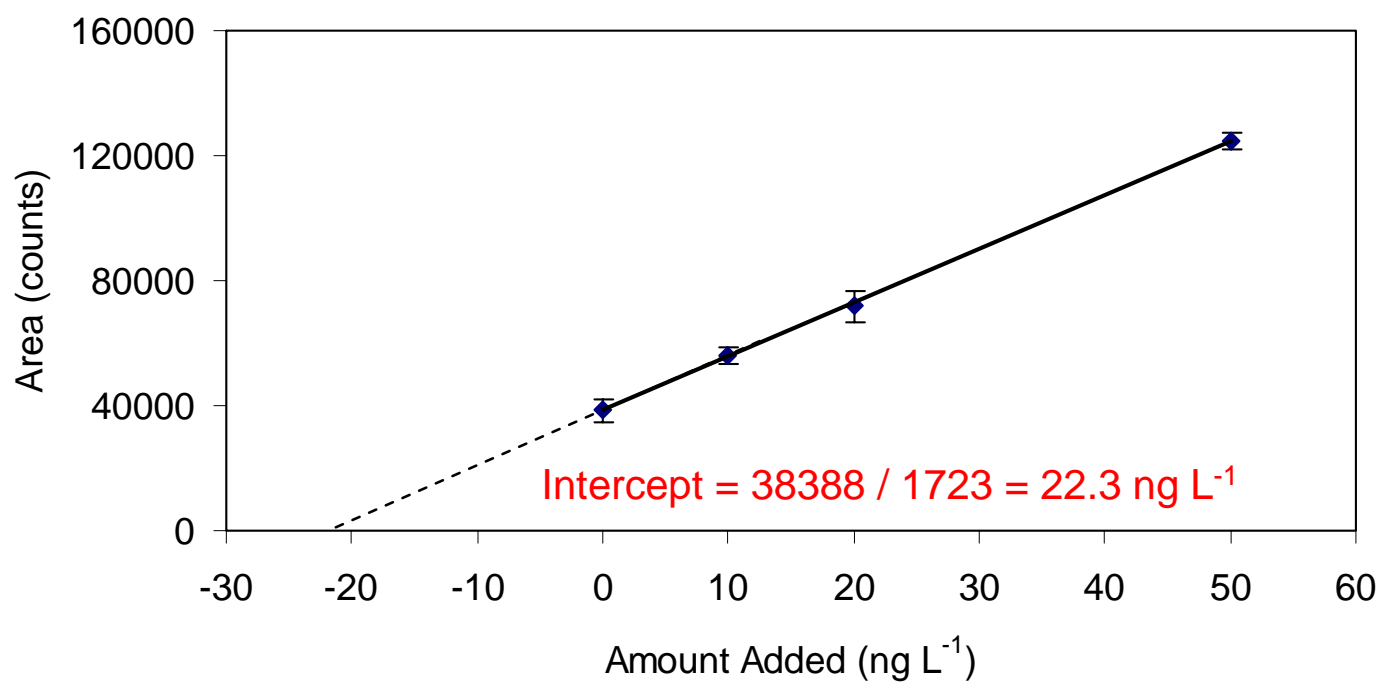

Concentration $\left(\mathrm{ng} \mathrm{g}^{-1}\right)=\left[\right.$ DF $x$ Intercept $\left(n g ~^{-1}\right) \times$ FV $\left.(L)\right] / m(g)=$

$$
=\left[50 \times 22.3 \times 10^{-3}\right] / 0.3785=2.9 \mathrm{ng} \mathrm{g}^{-1}
$$


Table S5. Overall analytical method uncertainty for each analyte (RSD), calculated for the internal standard (IS) method $(n=46)$ and standard addition (SA) method $(n=15)$.

\begin{tabular}{ccc}
\hline Analyte & $\begin{array}{c}\text { Uncertainty IS method } \\
(\mathbf{\%})\end{array}$ & $\begin{array}{c}\text { Uncertainty SA method } \\
(\%)\end{array}$ \\
\hline PFHpA & 10 & 14 \\
PFOA & 9 & 12 \\
PFNA & 4 & 7 \\
PFDA & 4 & 4 \\
PFUnA & 4 & 4 \\
PFDoA & 5 & 3 \\
PFTrA & 12 & - \\
PFTeA & 5 & 7 \\
PFPA & 17 & - \\
PFHxS & 13 & 22 \\
PFOS & 8 & 16 \\
PFDS & 10 & 9 \\
PFOSA & 9 & - \\
$8: 2$ FTUCA & 5 & 5 \\
$10: 2$ FTUCA & 3 & \\
\hline
\end{tabular}




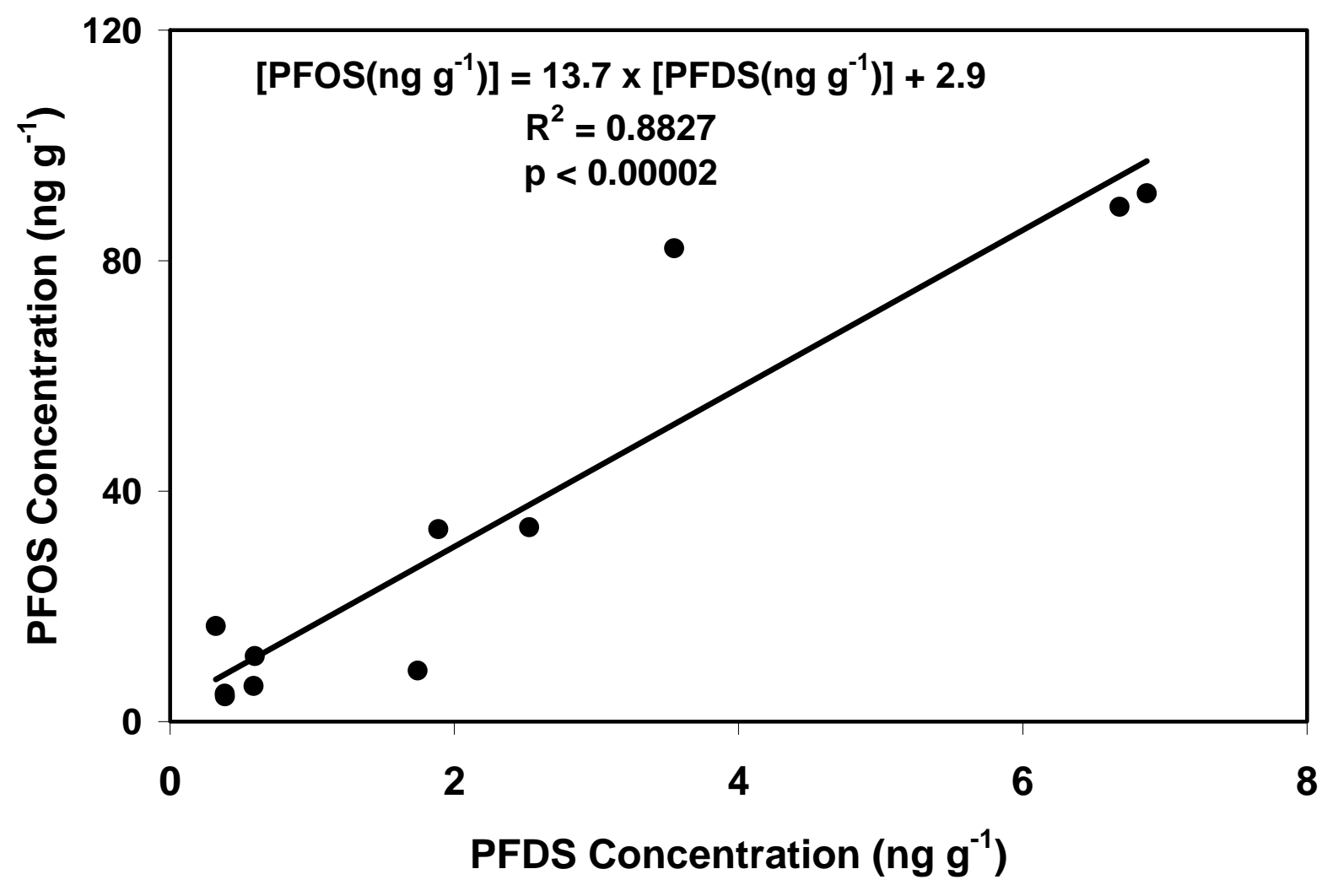

FIGURE S1. Correlation between the level of PFOS and PFDS in whole body homogenates of lake trout from the Great Lakes $(\alpha=0.05)$. The values were determined using the standard addition method and the extracts with non detectable responses for PFDS were excluded from this plot. 


\section{STATISTICS}

Graphs and results of the paired t-test for each analyte determined with standard addition and internal standard. P-values less than 0.05 indicate a statistically significant difference.
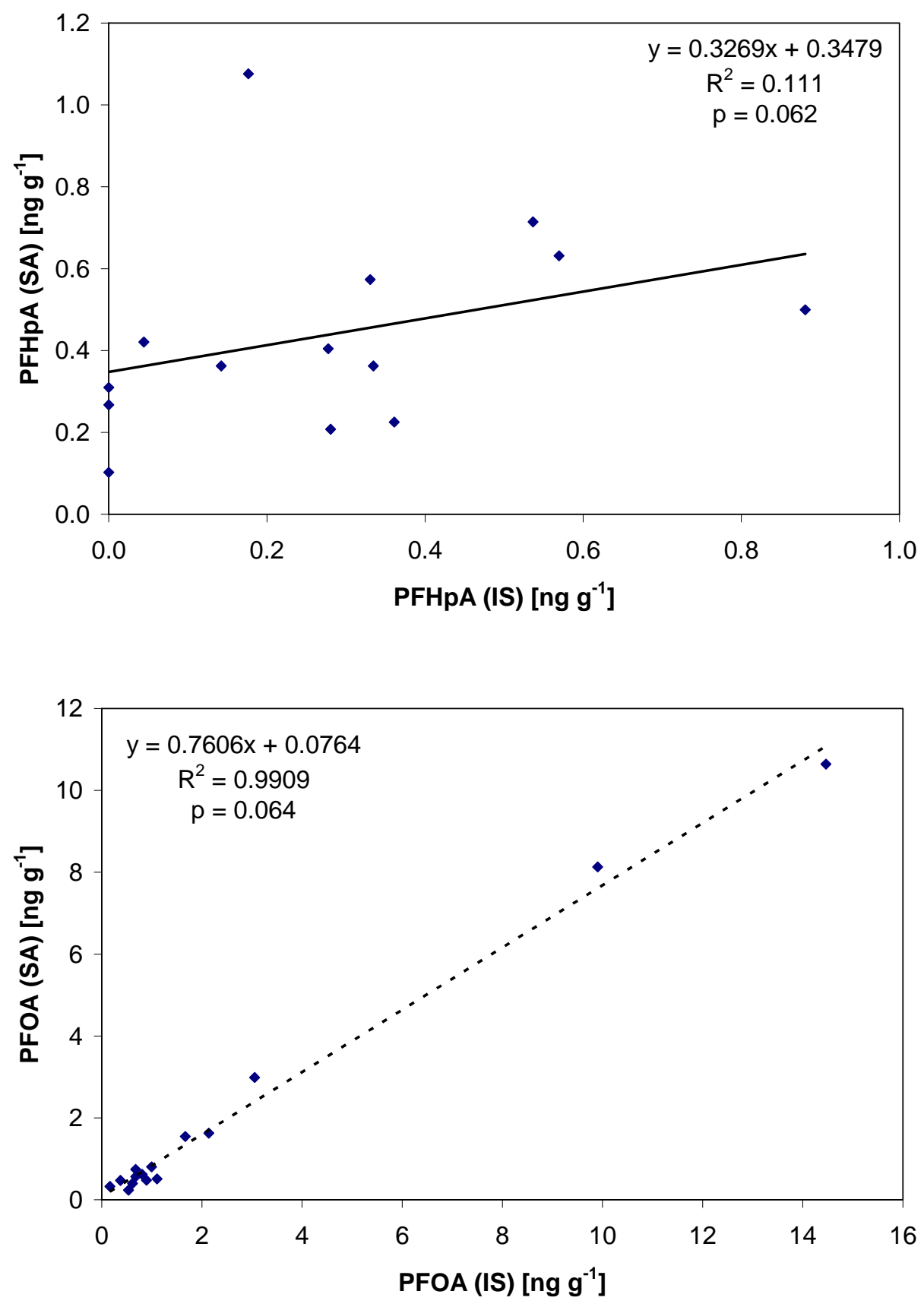

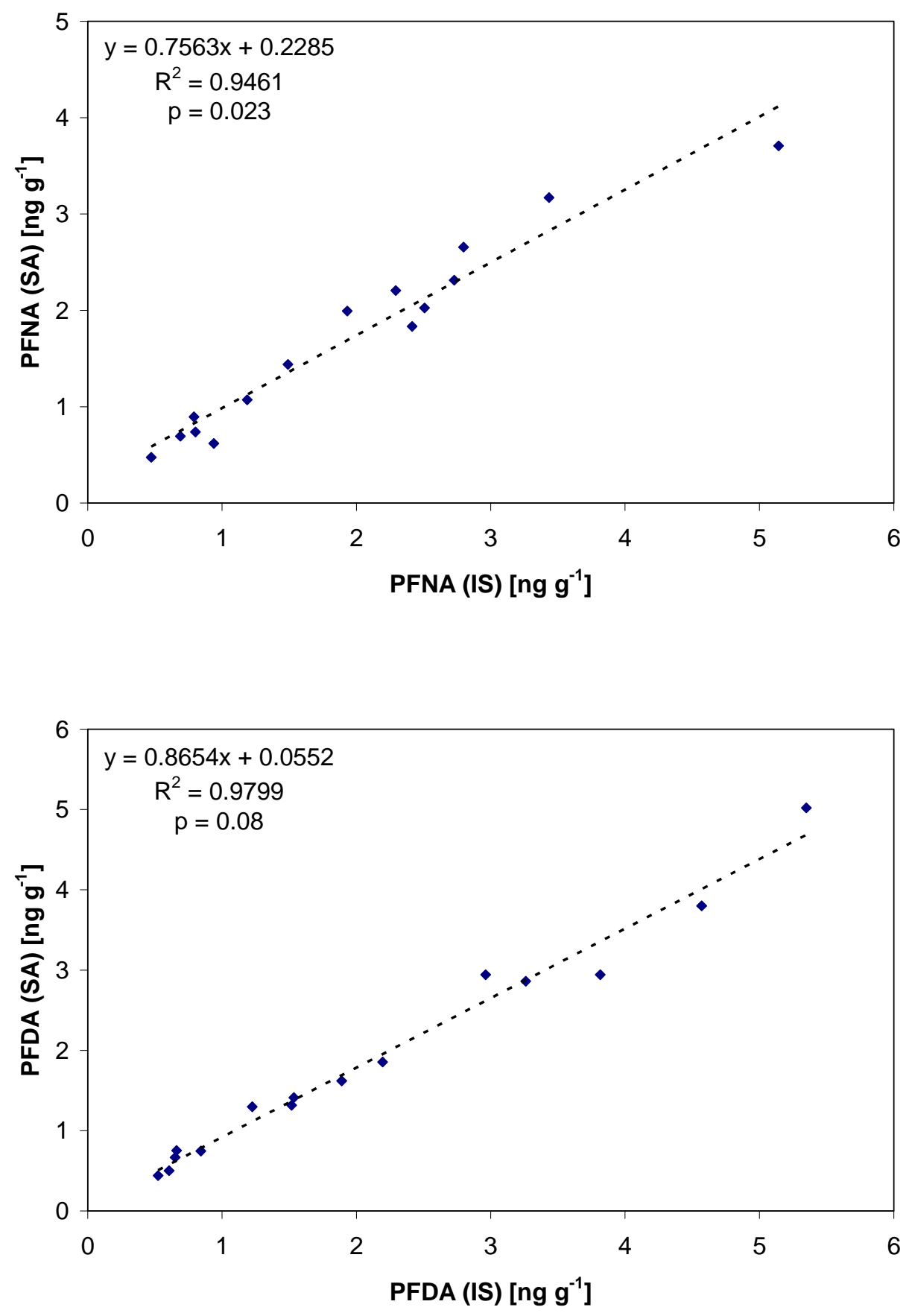

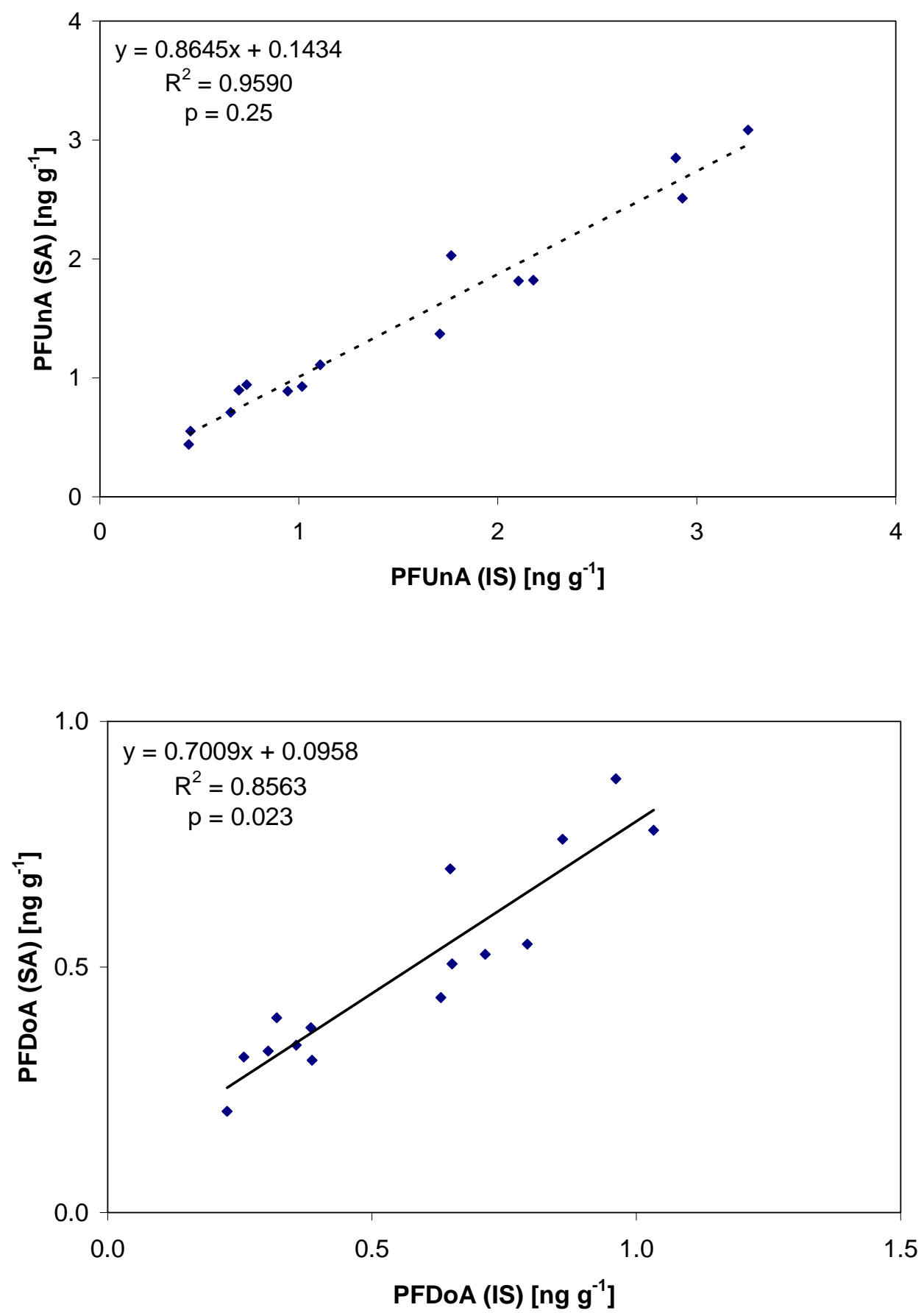

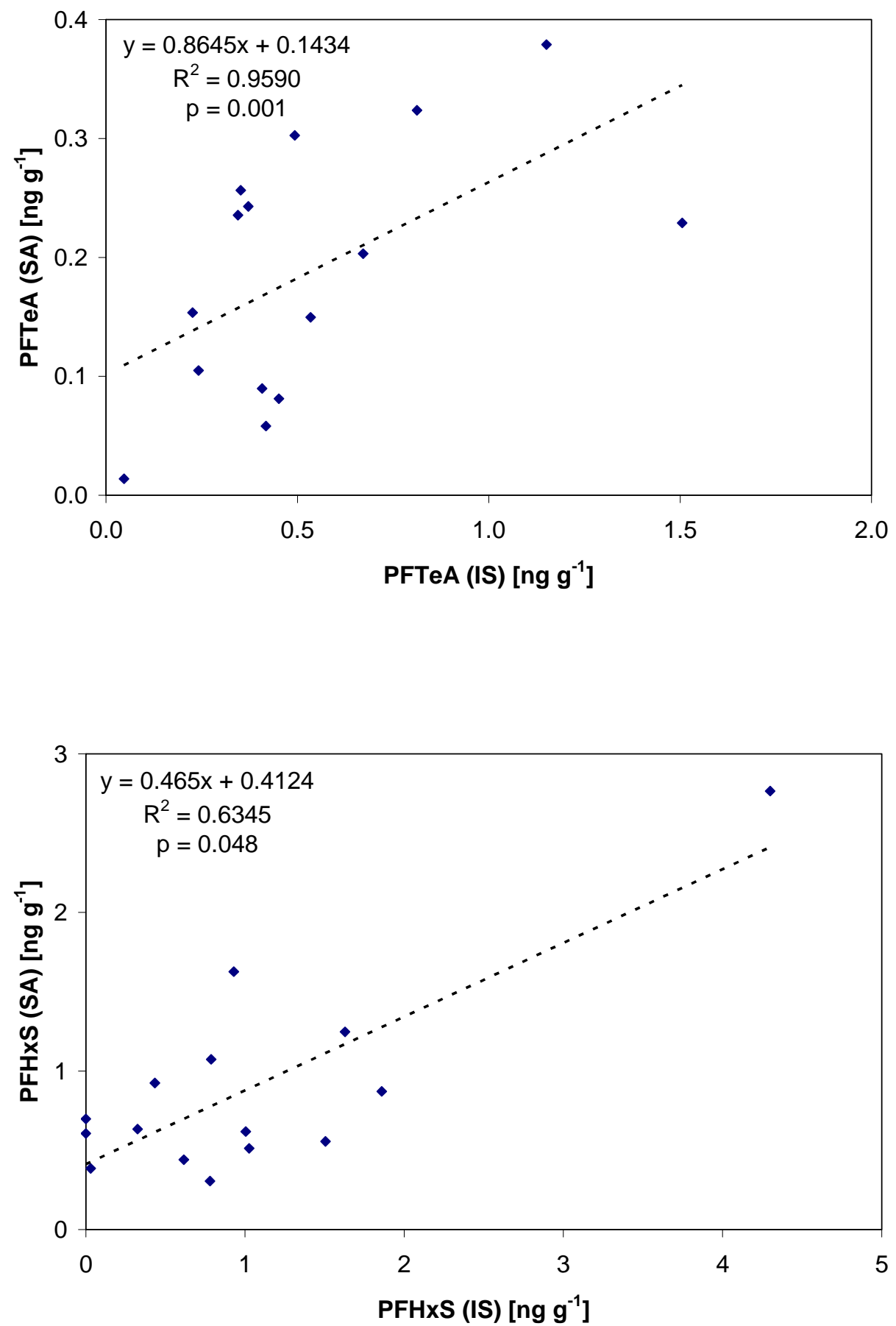

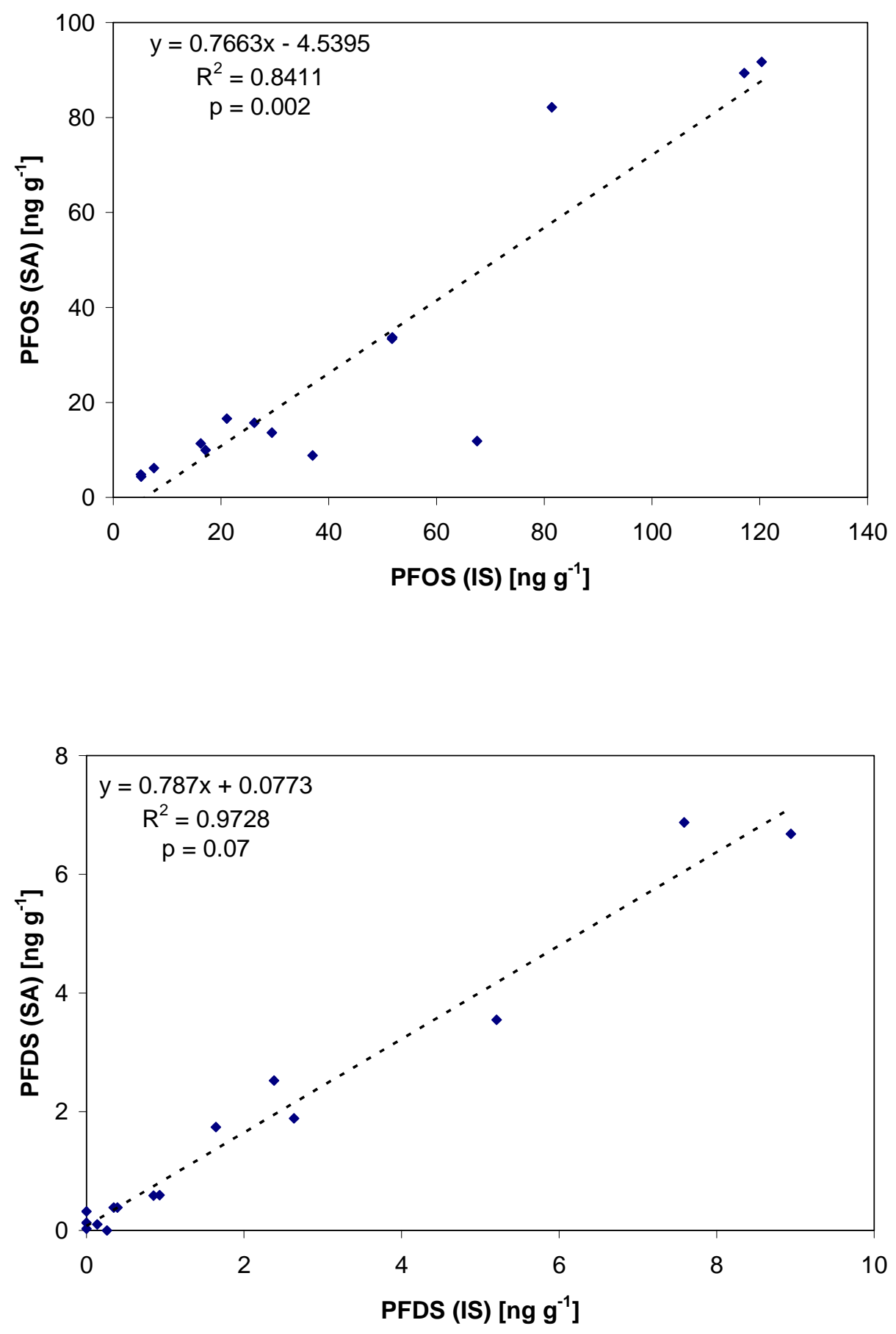


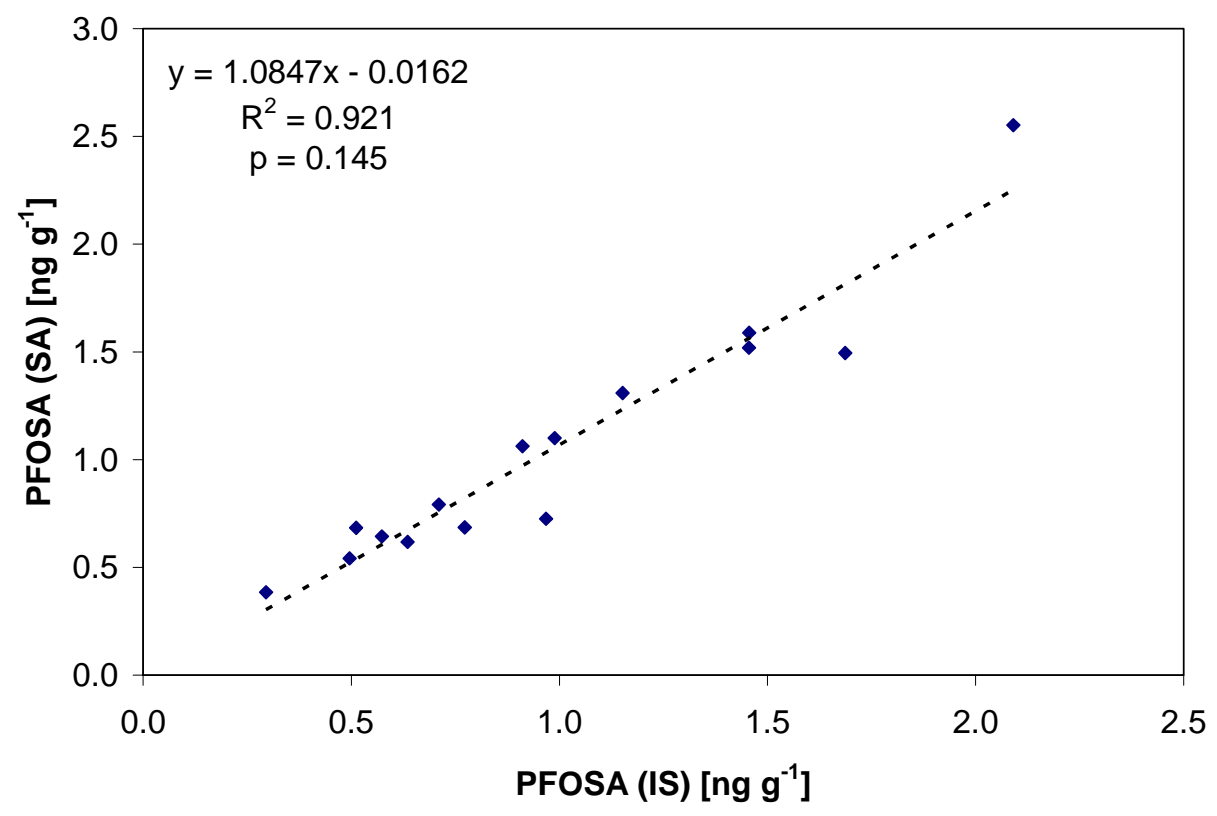

Table S6: Average Concentrations of PFCs in water samples (ng $\left.\mathrm{L}^{-1} \pm \mathrm{SE}\right)$ from the Great Lakes used to calculate the BAFs

\begin{tabular}{lccccccc}
\hline & $\begin{array}{c}\text { No } \\
\text { Samples }\end{array}$ & PFHxS & PFOS & PFOSA & PFOA & PFNA & PFDA \\
\hline Superior * & 3 & $0.3 \pm 0.1$ & $0.2 \pm 0.1$ & $0.1 \pm 0.03$ & $0.6 \pm 0.2$ & $0.2 \pm 0.01$ & $0.1 \pm 0.05$ \\
Huron* & 6 & $0.7 \pm 0.3$ & $2.5 \pm 0.2$ & $0.2 \pm 0.1$ & $0.4 \pm 0.2$ & $0.8 \pm 0.3$ & $0.4 \pm 0.2$ \\
Erie* & 3 & $3.2 \pm 2.1$ & $4.5 \pm 0.4$ & $0.3 \pm 0.2$ & $1.9 \pm 0.2$ & $0.4 \pm 0.1$ & $0.1 \pm 0.05$ \\
Ontario* & 10 & $0.7 \pm 0.6$ & $5.9 \pm 1.0$ & $0.1 \pm 0.05$ & $3.5 \pm 1.1$ & $0.8 \pm 0.3$ & $0.3 \pm 0.2$ \\
Michigan** & 4 & & $2.2 \pm 0.7$ & & $1.8 \pm 1.2$ & & \\
\hline
\end{tabular}

*(31) Furdui, V. I.; Crozier, P. W.; Reiner, E. J.; Mabury, S. A. In Organohalogen Compounds, CDRom of Proceedings of Dioxin 2005 and ISPAC-20; Reiner, E. and Alaee, M., Ed.: Toronto, Canada, 2005; 67, CD ID-1960, pp 211-214.

**(32) Simcik, M. F.; Dorweiler, K. J.; Ratio of perfluorochemical concentrations as a tracer of atmospheric deposition to surface waters. Environ. Sci. Technol. 2005, 39, 8678-8683. 